АНДРИАНОВ Валерий Валентинович - кандидат политических наук, доцент департамента политологии факультета социальных наук и массовых коммуникаций Финансового университета при Правительстве РФ (125993, Россия, г. Москва, ГСП-3, Ленинградский пр-кт, 49, vvandrianov@ fa.ru)

\title{
ЛОВУШКА НЕФТЕЭТАТИЧЕСКОЙ МОДЕЛИ: УРОКИ ВЕНЕСУЭЛЫ
}

\begin{abstract}
Аннотация. В статье на примере Венесуэлы анализируется влияние параметров распределения нефтяной ренты на социально-политические процессы. Доказывается, что периоды падения мировых нефтяных цен приводили к возникновению политической нестабильности в Венесуэле и в ряде случаев - $к$ смене политического режима. Электоральная поддержка действующих режимов обеспечивалась за счет расширения числа получателей ресурсной ренты при одновременном сокращении ее объема в расчете на каждого из бенефициаров. Возможности дальнейшего развития данной модели исчерпаны, размер нефтяной ренты уже недостаточен для обеспечения широкой электоральной поддержки действующей власти.
\end{abstract}

Ключевые слова: нефтеэтатическая модель, Венесуэла, кризис, социальный слой, электоральная поддержка

$\mathrm{P}$ асхожий тезис о «сырьевом проклятии» в последние десятилетия остается весьма популярным в общественных дискуссиях и служит предметом многочисленных научных исследований. Действительно, рост доходов от экспорта углеводородного сырья порождает как экономические последствия (так называемая голландская болезнь), так и социальные и политические эффекты.

Ярким примером может служить Венесуэла, которая стала, по сути, первым крупным экспортером нефти в мировом масштабе. Еще с первой половины XX в. нефтяной фактор начал оказывать существенное влияние на все сферы жизни этого латиноамериканского государства и привел к формированию такого феномена, как нефтеэтатическая модель (исп. - petroestado). Данная модель на протяжении десятилетий служит ловушкой, в которой неизменно оказывается политика практически всех правящих режимов страны - от военных диктатур до демократических правительств.

Анализ уроков Венесуэлы, связанных с ловушкой нефтеэтатической модели, представляется важным на фоне социально-экономической политики России, направленной на снижение зависимости ВВП от нефтяных доходов и диверсификации экономики страны. Данный опыт может быть также актуален в свете дискуссии о возможностях использования так называемой нефтегазовой ренты с целью поддержания политической стабильности в обществе, снижения социальной напряженности и повышения уровня жизни наиболее бедных слоев населения. Практика Венесуэлы демонстрирует, что решение перечисленных благородных задач за счет нефтяных сверхдоходов может привести страну в социально-политическую ловушку.

\section{Архитектор нефтеэтатической модели}

Период зарождения нефтеэтатической модели в Венесуэле можно датировать вторым десятилетием XX в., когда началось развитие двух тесно взаимоувязанных процессов - создание национальной нефтяной промышленности и решительное укрепление центральной власти в стране. 15 апреля 1914 г. компания Caribbean Petroleum (впоследствии приобретенная международным концерном 
Royal Dutch Shell) открыла на озере Маракайбо первое крупное месторождение нефти в Венесуэле, получившее название Mene grande.

Одновременно происходили коренные перемены в политической сфере страны. В декабре 1908 г. в результате государственного переворота был свергнут президент Сиприано Кастро (1858-1924), проводивший жесткую протекционистскую политику и препятствовавший проникновению в страну крупного иностранного капитала. Пришедший к власти при поддержке США бывший соратник С. Кастро генерал Хуан Висенте Гомес (1857-1935) зарекомендовал себя как проводник экономических интересов иностранных корпораций, в первую очередь нефтегазовых. Именно Гомеса, находившегося у власти в стране 27 лет, можно назвать архитектором нефтеэтатической модели.

На первом этапе построения нефтеэтатической модели ее главными бенефициарами являлись крупные латифундисты, действовавшие в связке с представителями политической элиты страны, и иностранные нефтяные компании. Поскольку принцип национального суверенитета над недрами страны, провозглашенный еще в 1829 г. Симоном Боливаром, запрещал передавать иностранцам земельные участки для поиска и добычи полезных ископаемых, посредниками в этом процессе выступили крупные землевладельцы и политики.

Задача широкого привлечения иностранного капитала на приемлемых для национальных элит условиях, с одной стороны, обусловливала необходимость обеспечения внутриполитической стабильности как одного из ключевых факторов благоприятного инвестиционного климата. С другой стороны, только поток капиталов из-за рубежа мог служить экономическим фундаментом такой стабильности. Именно подобная взаимосвязь позволила режиму Гомеса начать процесс укрепления центральной власти и наступления на экономические интересы региональных элит, так называемых каудильо, традиционно пользовавшихся практически безграничной властью на контролировавшихся ими территориях (аналогичная ситуация была характерна для многих стран Южной Америки в XIX - начале XX вв.).

X. Висенте Гомесу в целом удалось решить задачи, поставленные перед ним ходом венесуэльской истории: консолидировать нацию, свести к минимуму угрозу территориального распада страны, прекратить череду каудилистских переворотов, полностью погасить внешний долг страны и вывести Венесуэлу в число держав, с мнением которых приходилось считаться, в т.ч. США и странам Западной Европы. «Нефть и авторитарный режим позволили генералу Х. Висенте Гомесу добиться политической консолидации и стабилизации в разоренной длительной борьбой за независимость стране, экономика которой зависела от кофе и какао», - писал венесуэльский исследователь М. Куполо [Дабяган 1972: 44].

Но вместе с тем именно Гомес стал создателем «нефтеэтатической ловушки», в которую попала Венесуэла и из которой не может выбраться по сей день. Суть этой ловушки заключается в том, что любая модель распределения нефтяной ренты, используемая властями страны, позволяя решить тот или иной набор внешне- и внутриполитических задач, одновременно является источником возникновения новых острых политических конфликтов. Это наглядно продемонстрировали итоги правления Х. Висенте Гомеса. Венесуэльский диктатор заложил мину замедленного действия во внутренней политике, создав огромный потенциал конфликта между получателями нефтяной ренты и теми социальными слоями, которые были ею обделены. Широкие массы населения были лишены своей доли «нефтяного пирога» и накапливали недоволь- 
ство против политического режима, которое до поры до времени сдерживалось жесткими авторитарными методами генерала Висенте Гомеса. Эта мина рванула уже в день смерти диктатора, когда в декабре 1935 г. по стране прокатилась волна народных волнений и погромов. Закрытые анклавы западных нефтяных компаний на протяжении нескольких дней подвергались настоящей осаде со стороны беднейших слоев населения. А длившаяся около полутора месяцев забастовка работников нефтяной отрасли фактически перечеркнула репутацию Венесуэлы как одного из самых надежных поставщиков углеводородного сырья на мировой рынок.

\section{Накопление конфликтного потенциала}

Перед пришедшими на смену диктатуре Гомеса новыми политическими режимами встала проблема перераспределения ресурсной ренты в интересах более широких слоев населения с целью урегулирования внутриполитического конфликта. Уже в 1936 г. вошедший в новое правительство молодой экономист Альберто Адриани выдвинул концепцию, которую его коллега по правительству и писатель Услар Пьетри назвал «сеять нефть» (Sembrar petroleo). Суть ее заключалась в необходимости использования ресурсной ренты не для реализации каких-либо внешнеполитических амбиций, а для ускоренной модернизации народного хозяйства страны. Данный лозунг на протяжении многих десятилетий оставался «на знамени» венесуэльских политиков различной политической ориентации, в т.ч. присутствовал в риторике венесуэльского лидера Уго Чавеса.

Данная попытка выхода из «нефтеэтатической ловушки» представлялась весьма многообещающей, т.к. модернизация национальной экономики за счет нефтяной ренты позволила бы расширить круг ее конечных получателей и снизила бы остроту конфликта между различными социальными слоями. Но реализация провозглашенного принципа оказалась далекой от идеала. Новые подходы к перераспределению нефтяной ренты предполагали решение двуединой задачи: а) увеличение ее объемов путем последовательного наступления на интересы иностранных корпораций и б) повышение благосостояния широких слоев населения за счет реализации политики «сеяния нефти». С первой задачей с различной долей успеха справлялись практически все наследники Висенте Гомеса, включая и демократические режимы, и военные хунты.

Тем не менее страна по-прежнему не могла выйти из «нефтеэтатической ловушки», выражавшейся в накоплении внутреннего конфликтного потенциала, обусловленного неравным доступом различных слоев наслоения к нефтяной ренте. Решительно вырваться из нее попытались различные правительства страны в 1970-1980-х гг.

\section{Средний класс как новый бенефициар нефтеэтатической модели}

В начале 1970-х гг. благодаря наращиванию добычи нефти и повышению мировых нефтяных котировок вследствие череды ближневосточных кризисов Венесуэла по темпам экономического развития вышла на одно из первых мест в Латинской Америке. Ее ВВП на протяжении 1960-х гг. удвоился. По данному показателю страна заняла 4-е место на континенте, а по объему ВВП на душу населения - на 1-е место. Приток нефтедолларов позволил венесуэльскому правительству создать значительные накопления для финансирования экономики. Середина 1960-х - начало 1970- г. стали временем реализации грандиозных экономических проектов, существенно сократилась безработица.

Повышению объемов нефтяной ренты значительно способствовали национализация нефтяной промышленности, осуществленная в августе 1975 г. 
правительством президента Карлоса Андреса Переса (1922-2010), и создание на базе Венесуэльской нефтяной корпорации государственной компании «Петролеос де Венесуэла» (Petróleos de Venezuela).

Резкое и достаточно неожиданное повышение благополучия венесуэльской экономики породило определенную эйфорию в обществе и в правящих кругах страны и создало предпосылки для формирования доктрины «великой Венесуэлы». Как отмечал исследователь К. Майданик, «первый взлет цен на нефть в 1973-1974 годах, а затем и национализация нефтяной промышленности привели к резкому качественному наращиванию всех элементов и блоков “нефтеэтатической клиентелярно-субсидарной" модели, разгулу расходов и потребления. Пробил час “великой Венесуэлы". За три года удвоился ВВП страны, утроились доходы бюджета, учетверились поступления валюты и впятеро выросли валютные резервы. За пять лет втрое выросли и расходы правительства. Наступили годы подлинного “Эльдорадо” для среднего класса и максимального расширения - “вниз” его границ» [Майданик 1997].

Но именно в период 1970-1980-х гг. в наиболее яркой форме проявились все черты «ловушки нефтеэтатической модели». С одной стороны, резкое расширение числа получателей ресурсной ренты создавало иллюзию высокой консолидации венесуэльского общества, широкой поддержки демократических правительств со стороны населения. С другой стороны, благосостояние появившегося в стране многочисленного среднего класса базировалось не на диверсифицированном развитии различных отраслей экономки, совершенствовании ее качественной структуры и повышении производительности труда, а лишь на увеличении нефтяных доходов страны на фоне благоприятной конъюнктуры мирового рынка углеводородного сырья. Причем политическую поддержку новорожденного среднего класса, еще слабо осознававшего как истоки своего благосостояния, так и долгосрочные последствия безудержного роста потребления, властям страны приходилось покупать за счет все больших объемов ресурсной ренты в ущерб решению других экономических и социальных задач.

\section{Системный кризис нефтеэтатической модели}

Процесс роста нефтяных доходов, хотя и растянувшийся на два десятилетия, имел свои естественные пределы, обусловленные закономерностями развития мирового рынка, и рано или поздно должен был завершиться со всеми вытекающими последствиями для экономики и общества Венесуэлы. Как отмечал профессор Института Симона Боливара (Каракас) Хосе Висенте Карраскеро, «рента, получаемая за счет добычи нефти, в течение первых 20 лет демократии помогала демократическим правительствам с успехом обеспечивать потребности населения. Но несмотря на это, развитие, вызванное национализацией нефтяной промышленности и ростом мировых цен на нефтяное сырье, сопровождалось утечкой капитала, ростом внешнего долга и коррупционными скандалами. Как следствие, правительства были вынуждены увеличивать расходы, которые с каждым разом становились все более неэффективными... За бюджетным кризисом последовали девальвация и конец эры, известной как “великая Венесуэла"» [Carrasquero Aumaitre 2002: 5].

Обвал мировых нефтяных цен в начале 1986 г., происшедший после отказа Саудовской Аравии от роли замыкающего поставщика, тяжело отразился на Венесуэле: объем ее нефтяных доходов вновь резко упал. Середину 1980-х гг. можно образно охарактеризовать как «период застоя» или, как называют ее в венесуэльской политической науке, «перепутья». Экономическая и политическая система страны существовала за счет запаса прочности, накопленного 
в предыдущую эпоху. Правительство президента Хайме Лусинчи (1984-1989) стремилось к проведению популярной, но абсолютно неэффективной политики. В обществе нарастали пессимистические настроения.

Стало очевидным, что значительно сократившихся объемов нефтяной ренты явно недостаточно ни для обеспечения стабильности национальной экономики, ни для поддержания уже ставшего привычным уровня жизни среднего класса. Это вынудило Карлоса Андреса Переса, в 1999 г. вновь избранного президентом, совершить решительную попытку вырваться из «нефтеэтатической ловушки». Глава государства принял решение сделать это за счет проведения неолиберальных реформ, представлявших собой резкий контраст с прежней патерналистской политикой, базировавшейся на щедром распределении ресурсной ренты. Политика «большого виража», провозглашенная Пересом, вылилась в широкое недовольство того самого среднего класса, который еще недавно был надежной опорой демократических правительств Венесуэлы. 27 февраля 1989 г. в Каракасе, а затем и в ряде других крупных городов страны начались беспорядки, массовые грабежи и поджоги. Власти вывели на улицы войска. По официальным данным, погибло свыше 250 чел., по информации ряда независимых экспертов - до 500, около 1000 получили ранения. В столице впервые за 30 с лишним лет был введен комендантский час. Парламент страны принял решение о временном частичном ограничении конституционных прав и свобод. Данные события можно расценивать как первый наглядный признак кризиса демократической системы в Венесуэле.

Отчасти агония нефтеэтатической модели смогла продолжиться благодаря тому, что захват Ираком Кувейта и последовавшая за этим операция «Буря в пустыне» привели к всплеску мировых нефтяных цен и увеличению нефтяных доходов Венесуэлы. Однако курс неолиберальных реформ привел к снижению уровня жизни широких масс населения. На фоне значительного роста доходов политической и экономической элиты страны стали очевидными вопиющие социальные диспропорции. И это послужило предпосылкой развития политических процессов, направленных на очередное перераспределение нефтяной ренты, следствием чего явилось фактическое возвращение страны во все ту же «нефтеэтатическую ловушку». Прибегая к образному сравнению, можно сказать, что лечение тяжелобольного сводилось к увеличению ежедневной дозы лекарств, т.е. все новые и новые экономические трудности правительство стремилось решить при помоши дополнительных ассигнований за счет притока нефтедолларов.

\section{Новая модель ловушки}

Кризис нефтеэтатической модели в конце 1990-х гг. привел не к ее демонтажу, а к очередной трансформации. На фоне фактического размывания среднего класса (в силу описанных выше процессов) в Венесуэле на первый план вышли левые силы, возглавляемые бывшим военным Уго Чавесом. Целью провозглашенной им Боливарианской революции было де-факто перераспределение ресурсной ренты в пользу беднейших слоев населения в ущерб как олигархии, так и среднему классу. Значительно увеличившийся вследствие неолиберальных реформ 1980-1990-х гг. люмпенизированный слой населения стал основной социальной базой реформ Уго Чавеса, победившего на президентских выборах 5 декабря 1998 г. Поскольку материальные запросы беднейших слоев гораздо скромнее, чем среднего класса, даже сократившийся объем ресурсной ренты позволял формировать широкий круг сторонников новой власти.

Иными словами, в стране появился третий по счету адресант и бенефициар ресурсной ренты. Если на первом этапе (до середины XX в.) это были земельная 
аристократия и политическая элита страны, на втором этапе (1970-1980-е гг.) - значительно разросшийся средний класс, то теперь, на третьем этапе, эту роль стали играть беднейшие люмпенизированные слои населения, характеризующиеся как относительной скромностью запросов, так и многочисленностью, что обеспечивало достаточно прочную социальную базу Уго Чавесу, его сторонникам и последователям.

Одновременно новые власти страны были вынуждены вступить в конфликт с прежними бенефициарами ресурсной ренты - зарубежными нефтяными компаниями, крупным национальным капиталом и даже со средним классом (той его частью, которая не перешла в беднейшие слои в результате неолиберальных реформ). Можно полностью согласиться с мнением кубинского исследователя Элио Лопеса Веласа, что «слабая венесуэльская демократия, заключенная в рамки так называемой популистской системы, базирующейся на соглашении элит, была сильнейшим образом поколеблена из-за сокращения государственных доходов вследствие падения цен на нефть. Это подточило те институциональные основы, на которых покоилась демократическая система Венесуэлы» [Lopez 2001: 36].

В целях реализации своей политики Уго Чавес провел национализацию в целом ряде отраслей. Динамика данного процесса активизировалась после переизбрания Чавеса президентом на новый срок (декабрь 2006 г.). Под полный контроль государства перешла нефтяная промышленность страны.

Итоги перераспределения ренты в ходе Боливарианской революции можно расценивать двояко. С одной стороны, проводимая новым президентом политика позволила создать новые рабочие места и сократить безработицу с 16,6\% в 1998 г. до 7,7\% в 2009 г. В тот же период существенно (на 88\%) повысился размер минимальной заработной платы, до 500 долл. (по данному показателю Венесуэла вышла на 1-е место в Латинской Америке). Уровень бедности значительно снизился и в 2009 г. составлял 11,8\% [Строганова 2011: 246].

С другой стороны, конфликт с иностранными нефтегазовыми корпорациями и с менеджментом государственной компании «Петролеос де Венесуэла» привел к затяжному кризису в нефтяной промышленности страны и, как следствие, к падению добычи углеводородного сырья и сокращению объема нефтяной ренты. Иными словами, социально-экономическая политика Чавеса нанесла существенный урон той самой материально-экономической базе, на которую она и опиралась, т.е. значительно сузила возможности получения и дальнейшего распределения среди широких слоев населения доходов от деятельности национальной нефтяной промышленности.

Однако, по мнению автора, Уго Чавесу на фоне обострения политических отношений с официальным Вашингтоном все же долгое время удавалось не переходить определенную грань и сохранять торговое партнерство с главным покупателем венесуэльской нефти - США. Данная взаимозависимость в нефтяной сфере долгое время служила дополнительным фактором, обеспечивающим политическую стабильность режима Уго Чавеса. Но значение данного фактора существенно снизилось вследствие так называемой сланцевой революции в США. В результате заинтересованность Вашингтона в сохранении политической стабильности в Венесуэле любой ценой (в интересах поддержания регулярных нефтяных поставок) существенно ослабла.

\section{Будущее нефтеэтатической модели}

Тем не менее даже сократившийся объем нефтяной ренты и уже не сдерживаемое нефтяным фактором обострение отношений с США не стали причиной окончательного краха нефтеэтатической модели в Венесуэле. 
В 2004 г. на семинаре в Институте Латинской Америки РАН по итогам научной стажировки в Венесуэле автор высказал две гипотезы, вызвавшие определенную долю сомнения у коллег. Первая из них заключалась в том, что установившаяся в Венесуэле политическая система, созданная Уго Чавесом, имеет достаточно высокий потенциал прочности, поскольку базируется на распределении ресурсной ренты среди максимально широких слоев населения, тем самым гарантируя электоральную поддержку действующему президенту со стороны массы наименее обеспеченных граждан. При этом уровень данной поддержки будет сохраняться даже на фоне социально-экономической деградации страны, поскольку распределяемая без всяких дополнительных условий и ограничений рента «покупает» лояльность тех граждан, которые десятилетиями оставались за бортом относительно процветавшей экономики Венесуэлы (в 1970-1980-х гг.). Вторая гипотеза сводилась к тому, что уход с политической арены самого Уго Чавеса (в результате покушения или по естественным причинам) не приведет к немедленному демонтажу созданной им системы. Наоборот, во главе страны скорее всего окажется политик еще более леворадикальных взглядов, чем сам Чавес, который будет стремиться увеличить объемы безвозмездного распределения ресурсной ренты.

Не претендуя на лавры пророка, хотелось бы констатировать, что в целом эти гипотезы нашли свое подтверждение. При этом можно отметить, что новый лидер страны Николас Мадуро, уступающий по уровню харизмы и дипломатических талантов своему предшественнику, стремясь получить все больше средств для раздачи своему электорату, был вынужден нарушить созданный Уго Чавесом хрупкий баланс между интересами западных нефтяных компаний (читай - администрации США) и упомянутых широких слоев населения, заинтересованных в максимизации нефтяной ренты. Это ожидаемо привело к усилению встречного давления со стороны западных стран во главе с США и, как следствие, к снижению нефтедобычи в стране и падению нефтяных доходов. К середине 2020 г. производство нефти в Венесуэле обвалилось до 75-летнего минимума и составило всего 374 барр/сут. ${ }^{1}$

Соответственно, по данным Datanalisis, уровень поддержки президента среди $20 \%$ самых бедных жителей страны опустился с примерно 40\% в начале 2016 г. до $18 \%$ в феврале 2019 г. «Символически потеря поддержки жителей трущоб большая неудача для правительства», - отмечает политолог Военно-морской академии США Джон Полга-Хецимович ${ }^{2}$.

Можно поставить под сомнение данный тезис, о чем косвенно свидетельствуют результаты парламентских выборов в Венесуэле, прошедших 6 декабря 2020 г. По их итогам Николас Мадуро вернул себе контроль над Национальной ассамблеей. Коалиция «Великий патриотический полюс», которую возглавляет пропрезидентская Единая социалистическая партия Венесуэлы, набрала $67,7 \%$ голосов. Второе место получил «Демократический альянс», представляющий оппозиционные партии, он набрал 17,95\%. Третье место досталось альянсу «Объединенная Венесуэла» - 4,19\% голосов.

Электорат Мадуро, как представляется, отдает себе отчет, что новые попытки выхода из «нефтеэтатической ловушки» приведут лишь к очередному перераспределению нефтяной ренты, и явно не в интересах тех слоев, которые

1 Zerpa F. Venezuela's Oil Production Plunges to Lowest Level Since 1945. - Bloomberg. 13.06.2020. URL: https://www.bloomberg.com/news/articles/2020-06-12/venezuela-s-oilproduction-plunges-to-lowest-level-since-1945 (accessed 29.06.2021).

2 Luhnov D. Maduro loses grip on Venezuela's poor, a vital source of his power. - The Wall Street Journal. 19.03.2019. URL: https://www.wsj.com/articles/maduro-loses-grip-on-venezuelas-poora-vital-source-of-his-power-11553014207 (accessed 29.06.2021). 
сегодня поддерживают преемника Уго Чавеса. Образно говоря, лучше «сидеть в ловушке на урезанном пайке», ощущая себя при этом социальным гегемоном, чем с понурой головой отправится «на бойню» (стать объектом «экономической мести» со стороны неолиберального правительства, которое могло бы прийти на смену режиму Мадуро). Во многом именно этим (а не только антидемократическими и репрессивными мерами самого Мадуро) объясняется, на взгляд автора, сохранение нынешнего статус-кво вопреки многочисленным прогнозам об очень скором падении режима. Однако открытым остается вопрос, насколько длителен ресурс такой модели на фоне продолжающегося сжимания «шагреневой кожи» нефтяных доходов Венесуэлы.

Фактически ресурс нефтеэтатической модели уже исчерпан. Пройдя длительный цикл развития, на протяжении которого менялся социальный состав бенефициаров нефтяной ренты, она пришла сегодня к своей крайней точке. Дальнейшее расширение числа получателей ренты (как и увеличение ее объемов в расчете на каждого получателя) уже невозможно вследствие резкого падения доходов от нефтяной промышленности. А утрата Венесуэлой роли крупного и наиболее стабильного поставщика нефти на рынок США значительно ослабила геополитические позиции страны. Что придет на смену «ловушке нефтеэтатической модели»? Пока что этот вопрос остается открытым. Между тем дальнейшее развитие политических и социальных процессов в Венесуэле представляет большой интерес, как научный, так и практический, для государств, экономика которых в значительной степени зависит от доходов от экспорта углеводородного сырья.

\section{Список литературы}

Дабяган Э. С. 1972. Национал-реформизм в современной Венесуэле. М.: Наука. 273 с.

Майданик К.Л. 1997. От нефтеэтатической модели - куда? - Латинская Америка. № 1. С. 78-88.

Строганова Е.Д. 2011. Социально-политические преобразования Уго Чавеса в Венесуэле. - Берегиня. 777. Сова: научный журнал № 3(10). С. 246-250.

Carrasquero J. 2002. Venezuela: Democracia en Crisis? - Europa America Latina: Analisis e Informaciones. № 9. C. 5-10.

Lopez E. 2001. La revolucion bolivariana. De los actores hegemonicos a las bases del cambio. - Cuadernos de nuestra America. La Habana. Vol. XIV. No. 28.

\section{PETROLEUM MODEL TRAP: VENEZUELA LESSONS}

Abstract. Using the example of Venezuela, the article analyzes the impact of oil rent on socio-political processes. An analysis of the political history of Venezuela throughout the $20^{\text {th }}$ century indicates that one of the main factors in changing the political system was the size of the country's revenues from oil exports, as well as the parameters of the distribution of these revenues. Periods of falling world oil prices led to the emergence of political instability in Venezuela and, in some cases, to a change in the political regime.

In order to maintain social stability and ensure electoral support for the current political regimes, the Venezuelan authorities resorted to the redistribution of resource rent. The circle of recipients of resource rent was constantly expanding. At the first stage, in the first half of the $20^{\text {th }}$ century, these were large landowners and the countrys political elite. In 1960s-1970s, the 
middle class became the main recipient of the rent. During this period, Venezuelan society has reached the highest level of its stability and prosperity. At the turn of the $20^{\text {th }}$ and $21^{\text {st }}$ centuries, the poorest strata of Venezuelan society have become the new beneficiaries of the resource rent. At the same time, a social conflict was growing in the country between strata of the population who received their share of the resource rent and citizens who did not receive their share.

The possibilities for further development of this model have already been exhausted. The social crisis led to the degradation of the country's economy and oil industry. The amount of oil rent is already insufficient to ensure broad electoral support for the current government. The socio-political model of Venezuela has entered the stage of a deep crisis.

Keywords: petroetatic model (petroestado), Venezuela, crisis, social stratum, electoral support

ФАЙНШМИДТ Роман Иосифович - аспирант кафедры политологии и политического управления Института общественных наук Российской академии народного хозяйства и государственной службы при Президенте РФ (119571, Россия, г. Москва, пр-кт Вернадского, 82; faynshmidt-ri@ ranepa.ru)

\title{
ФАКТОРЫ РАДИКАЛИЗАЦИИ ИСЛАМА В ИНДОНЕЗИИ В КОНЦЕ ХХ - НАЧАЛЕ XXI в.
}

\begin{abstract}
Аннотация. В конце 1990-х - начале нулевых гг. в Индонезии получили распространение радикальные формы ислама, которые в ряде случаев были связаны с возникновением исламистских террористических группировок в различных частях страны. Подобное явление стало неожиданностью для международного сообщества, традиционно отождествляющего радикальный ислам с Ближним Востоком. Тем не менее развитие радикального ислама в Индонезии и его проявление в подобном формате порождено целым комплексом причин, рассмотренных в рамках данной статьи.
\end{abstract}

Ключевые слова: радикальный ислам, Индонезия, исламизм, Джемаа Исламия, терроризм

$\mathrm{K}$ началу XXI в. Индонезия является крупнейшим в мире государством по численности населения, исповедующего ислам. Так, в 2010 г. из 237,64 млн населения страны 207,18 млн относили себя к мусульманам ${ }^{1}$. В то же время Индонезия также известна и распространением радикальных форм ислама, нередко выражающихся в террористической активности отдельных группировок. Наибольшую известность среди террористических группировок получила Джемаа Исламия (Jemaah Islamiyah), известная своими связями с Аль-Каидой (запрещена на территории РФ), а также серией взрывов на о. Бали в октябре 2002 г. с общей численностью жертв более 200 чел. Кроме Джемаа Исламия, распространены такие сетевые группировки, как Джамаа Аншарут Таухид (Jamaah Ansharut Tauhid), Ласкар Джихад (Laskar Jihad), Муджахидин Индонезия Тимур (Mujahidin Indonesia Timur), Муджахидин КОМПАК (Mujahedeen KOMРАK) и ряд других. Иными словами, проблема исламского радикализма, в т.ч. и с участием вооруженных группировок, имеет особую актуальность для Индонезии, а само возникновение данного явления обусловлено целым комплексом факторов.

Прежде всего, следует обозначить, что Индонезия является полиэтническим и многоконфессиональным обществом. В число крупнейших этниче-

${ }^{1}$ Kewarganegaraan, Suku Bangsa, Agama, dan Bahasa Sehari-hari Penduduk Indonesia - Hasil Sensus Penduduk 2010 ['Nationality, Ethnicity, Religion, and Daily Language of Indonesian Population - Results of the 2010 Census']. Jakarta: Badan Pusat Statistik (BPS - Statistics Indonesia). October 2011. Р. 42-43 (на индонез. яз). 